\title{
Audit of Blood Transfusion Practice during Intraoperative Period in Adult Spine Surgery
}

\author{
Pallavi Waghalkar ${ }^{1}$, Manish Pawar ${ }^{2}$
}

\begin{abstract}
Background: Transfusion of blood is regarded as of key importance in the spinal procedure. In spite of increase in rate of spinal surgeries, the audit of blood transfusion throughout spinal procedures in regional traumatic centers is important. Therefore, the present study was undertaken to evaluate blood transfusion practices in adult spine surgeries and also determine the extent of utilization, wastage of blood products, and prescription of blood during spine surgery with the help of indices ( $\mathrm{C} / \mathrm{T}, \% \mathrm{~T}$, and $\mathrm{TI})$ for assessing blood ordering.

Materials and methods: A retrospective observational study among 130 patients was conducted to audit the blood transfusion practice during the intraoperative period for adult spine surgery over a period of 1 year. The rate of blood transfusion and indices of blood utilization were calculated.

Results: Out of 510 blood units cross-matched for 130 study subjects, just 112 units were transfused to 60 cases, indicative of only $46.15 \%$ of cases required transfusions of blood. We observed that factors related to a greater chance of transfusion of blood were preoperative hemoglobin, indication of surgery, surgical approach, and region of spine by Chi-square. Of all of these variables, only indication of surgery was relevant in the multivariate model. The transfusion probability (\%T), "transfusion index" (TI), and "cross-match transfusion (C/T) ratio" were 46.2, 0.86, and $4.5 \%$, respectively.

Conclusion: The independent factor associated with more number of blood transfusions was indication of surgery. Transfusion probability and $\mathrm{TI}$ in the present study are indicative of optimal utilization of blood. However, the high $\mathrm{C} / \mathrm{T}$ ratio suggests the over cross-matching, which should be minimized in future.

Keywords: Audit, Blood transfusion, Chi-square, Cross-match transfusion ratio, Hemoglobin, Indices, Spine surgery, Transfusion index, Transfusion probability.

Research and Innovation in Anesthesia (2020): 10.5005/jp-journals-10049-0087
\end{abstract}

\section{INTRODUCTION}

Blood is a valuable asset and the secret to successful management of blood bank services is its proper use. Transfusion of blood has a significant role in surgical patient resuscitation and treatment, but we frequently underestimate expected blood loss by overordering blood. ${ }^{1}$ However, transfusion of blood is measured as high importance in spinal procedures. In sight of increase in number of spinal processes due to road traffic accidents, pathological causes, the audit of blood transfusion throughout spinal procedures in regional traumatic centers is essential. Advancement in surgical procedures, method of hemostasis, as well as enhanced managing strategies have considerably decreased intraoperative transfusion requirement. ${ }^{2}$

There is wastage of time and efforts in cross-matching for each patient posted for spine surgeries as most of the cross-matched blood is not utilized for transfusion. Once cross-matched, the blood bag is kept in reserve, which leads to storage difficulties for blood center, decrease in lifespan, financial burden, and wastage of blood units [540]. There are various indices for evaluating blood assembling practice, such as "transfusion index" (TI), "transfusion probability" (\%T), and "cross-match/transfusion (C/T) ratio." They will help to reduce the extraordinary financial cost of ineffective blood recommendation practices. ${ }^{2}$

Now, we are more concentrated on identifying patients who are unlikely to need transfusion of blood during the surgical procedure, so this appeared to be the place where we could better minimize the cost of blood banks without sacrificing safety of patients. Also, we involve auditing cross-match to transfusion practices of our institute and compare them with other studies and analyze the
${ }^{1}$ Department of Anesthesiology, King Edward Memorial Hospital, Seth Gordhandas Sunderdas Medical College, Mumbai, Maharashtra, India ${ }^{2}$ Department of Anesthesiology, Seth Gordhandas Sunderdas Medical College, Mumbai, Maharashtra, India

Corresponding Author: Manish Pawar, Department of Anesthesiology, Seth Gordhandas Sunderdas Medical College, Mumbai, Maharashtra, India, Phone: +91 9137827177, e-mail: whyme109@gmail.com

How to cite this article: Waghalkar P, Pawar M. Audit of Blood Transfusion Practice during Intraoperative Period in Adult Spine Surgery. Res Inno in Anesth 2020;5(2):23-27.

Source of support: Nil

Conflict of interest: None

several preoperative factors that contribute to transfusion of blood for cases underwent spine surgeries.

\section{Materials and Methods}

The present retrospective observational study was conducted in the Department of Anesthesiology at Tertiary Care Institute during the 1-year period from Jan 1, 2016 to Dec 31, 2016. Overall 130 patients of ASA grade I, II, and III, having age between 18 and 60 years and who were scheduled for spinal cord or nerve root compression surgery and pathological spine surgery (congenital, degenerative, infective, traumatic, idiopathic) were enrolled to audit the blood transfusion practice during the intraoperative period. Patients with unsteady vertebral segment or reduced malformation as in scoliosis were also included. Patient whose notes not recovered, 
revision surgery, neoplastic surgery, and multiple surgeries were excluded from the study.

Anesthetic plans were revised for all the patients in contest with age, sex, ASA grading, lab investigations, indication of surgery, technique of anesthesia, position during surgery, operative approaches, operative time, number of vertebral levels, transfusion records, and intraoperative complications. Blood requisition and transfusion of spine surgery cases were compiled and reviewed with quantity of units equipped, cross-matched, and transfused, no. of patients cross-matched and transfused, source of blood donation or collection, and anesthesia type. All these records were collected from the operation theater registers, anesthesia-team record as well as blood bank record.

The blood transfusion rate and blood utilization indices-for example, $\mathrm{C} / \mathrm{T}, \mathrm{Tl}$, and \%T-were determined and utilized to compare different patient groups. Transfusion index of $\geq 0.5, \% \mathrm{~T}$ of $\geq 30 \%$, and $\mathrm{C} / \mathrm{T}$ ratio of $\leq 2.5$ are measured revealing judicious blood prescription practice and use.

\section{Statistical Analysis}

The statistical analysis was done by using SPSS ver. 20. Data were analyzed regarding number of blood units ordered for every case vs overall number of units transfused ( $\mathrm{C} / \mathrm{T}$ ratio). Continuous variables were presented as mean $\pm S D$, while categorical variables presented as numbers and percentage. We determined the relation between outcome (blood transfusion) and other study parameters (age, sex), utilizing the univariate analysis (Chi-square test, Fischer Exact test) where appropriate variables with $p$ value $\leq 0.2$ were involved in 'binary logistic regression model' to identify independent association with blood transfusion. The $p$ value less than 0.5 was considered statistically significant.

\section{Results}

Total 130 spine operations were done over a period of 1 year under consideration. Out of 130 patients, 70 (53.8\%) patients were male and 60 (46.2\%) were female. Average age of the patients was 40.4 \pm 12.13 years, with range of $18-60$ years. Most of the cases $(30.7 \%)$ were in 41-50 years of age group followed by 51-60 (23.9\%) and $31-40$ years ( $21.6 \%)$. The age and sex distribution of patients is summarized in Table 1.

Total 41 patients $(31.53 \%)$ had comorbidities such as hypertension (HTN) (16; 12.3\%), diabetes mellitus (DM) (12; 9.2\%), ischemic heart disease $+\mathrm{HTN}(8 ; 6.2 \%)$, and ischemic heart disease + DM (5; 3.8\%). The primary indication for surgery was degenerative spine disease $(61 ; 46.9 \%)$ followed by trauma $(26 ; 20 \%)$, adult idiopathic scoliosis (AIS) $(20 ; 15.4 \%)$, infection $(8 ; 6.2 \%)$, and others including Pott's disease (15; 11.5\%). Total 69 (53.1\%) patients had

Table 1: Age and sex distribution of patients

\begin{tabular}{llll}
\hline & Male & Female & Total \\
\cline { 2 - 4 } Age (in years) & $\begin{array}{l}\text { No. of patients } \\
(\%)\end{array}$ & $\begin{array}{l}\text { No. of patients } \\
(\%)\end{array}$ & $\begin{array}{l}\text { No. of patients } \\
(\%)\end{array}$ \\
\hline $18-20$ & $4(3.1)$ & $2(105)$ & $6(4.6)$ \\
$21-30$ & $13(10)$ & $12(9.2)$ & $25(19.2)$ \\
$31-40$ & $11(8.5)$ & $17(13.1)$ & $28(21.6)$ \\
$41-50$ & $21(16.1)$ & $19(14.6)$ & $40(30.7)$ \\
$51-60$ & $21(16.1)$ & $10(7.8)$ & $31(23.9)$ \\
Total & $70(53.8)$ & $60(46.2)$ & $130(100)$ \\
Mean \pm SD & $41.4 \pm 12.67$ & $39.3 \pm 11.46$ & $40.4 \pm 12.13$ \\
\hline
\end{tabular}

the surgical procedure via the posterior approach whereas residual patients undergo the process via the anterior approach (32.3\%), circumferential approach (7.7\%), and lateral approach (6.9\%). Maximum number of patients $(43 ; 33.1 \%)$ underwent cervical surgery are shown in Figure 1.

The mean duration of surgery was significantly less in male than female patients. However, the mean blood loss and mean hemoglobin levels were significantly more in male than female cases $(p<0.05)$ as shown in Table 2.

Total 510 blood units were cross-matched for 130 cases, 112 units were transfused to 60 cases, representing that only $46.15 \%$ of cases require transfusions of blood (Fig. 2).

When Chi-square was applied for comparison between no. of cases with cross-matched blood and demanding transfusion with respect to patient characteristic, it showed that factors related with a greater risk of transfusion of blood were preoperative hemoglobin, indication of surgery, surgical approach, and region of spine $(p<0.05)$ (Table 3). The multivariate analysis showed that the factors that were individually linked with greater risk of transfusion of blood was sign of operation ( $p<0.05$ ) (Table 4).

From Figure 2, we can derive the \%T of the spine operations by:

$$
\begin{aligned}
\% T= & (\text { Number of patients transfused } \times 100) / \\
& \text { Number of patients cross }- \text { matched } \\
= & 60 \times 100 / 130=46.2 \%
\end{aligned}
$$

The TI was derived by:

$$
\begin{aligned}
& \mathrm{TI}=\text { No. of units of blood transfused } / \\
& \text { No. of cases cross }- \text { matched }=112 / 130=0.86
\end{aligned}
$$

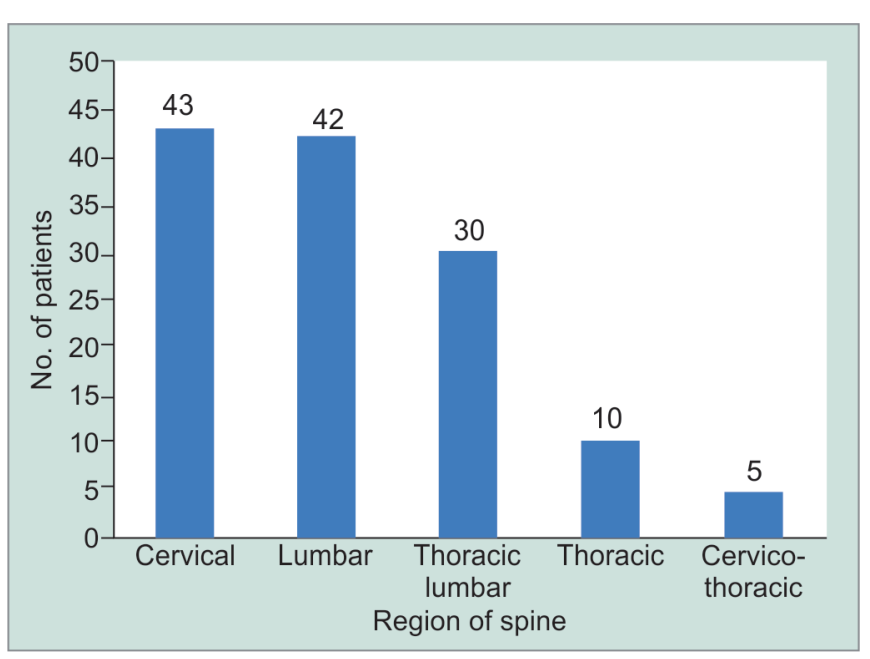

Fig. 1: Distribution of patients according to region of spine

Table 2: Mean duration of surgery, blood loss, and hemoglobin levels

\begin{tabular}{lcll}
\hline & Male & Female & Total \\
\hline $\begin{array}{l}\text { Mean duration } \\
\text { of surgery } \\
\text { (minutes) }\end{array}$ & $298.06 \pm 30.80$ & $319.77 \pm 28.04$ & $308.07 \pm 31.38$ \\
$\begin{array}{l}\text { Mean blood } \\
\text { loss (mL) }\end{array}$ & $830.55 \pm 28.38$ & $592.87 \pm 29.73$ & $720.85 \pm 122.41$ \\
$\begin{array}{l}\text { Mean hemo- } \\
\text { globin levels }\end{array}$ & $14.6 \pm 3.41$ & $12.09 \pm 3.37$ & $13.44 \pm 3.61$ \\
\hline
\end{tabular}




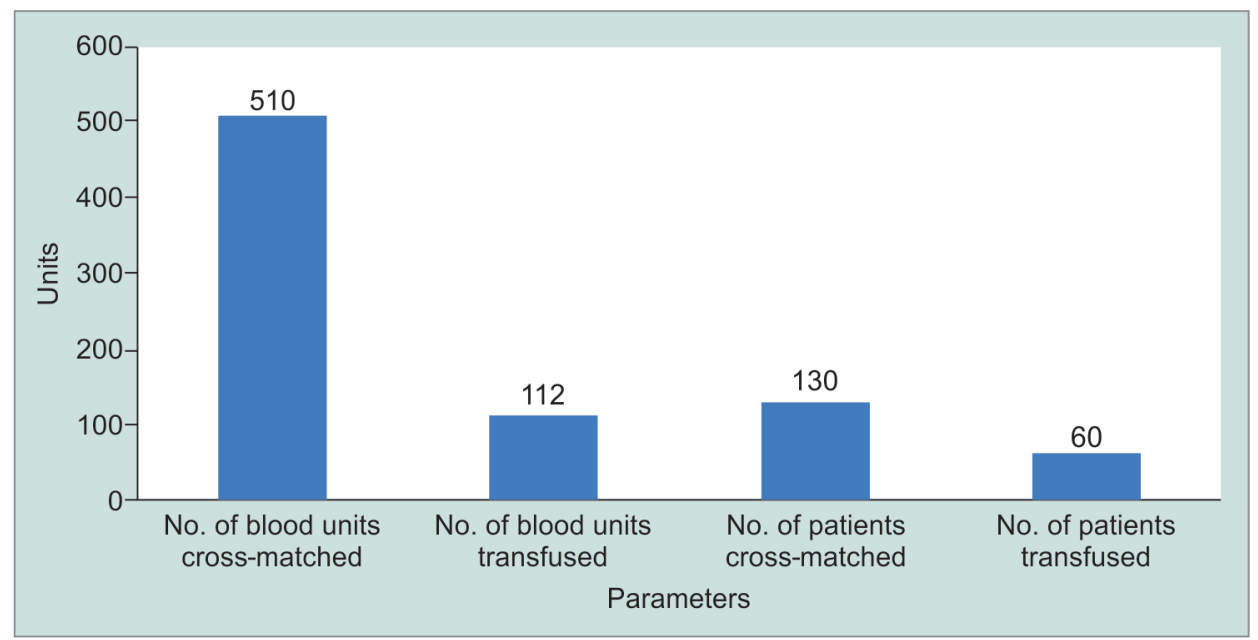

Fig. 2: Blood request and transfusion record of patients

Table 3: Chi-square comparison between number of patients with cross-matched blood and requiring transfusion with patients characteristic

\begin{tabular}{|c|c|c|c|c|}
\hline \multirow[b]{2}{*}{ Parameters } & & \multicolumn{2}{|c|}{ No. of patients } & \multirow[b]{2}{*}{ p value } \\
\hline & & Cross-matched & Transfused & \\
\hline \multirow[t]{2}{*}{ Age (in years) } & $\leq 40$ & $59(45.4)$ & $32(24.6)$ & $>0.05$ \\
\hline & $>40$ & $71(54.6)$ & $28(21.5)$ & \\
\hline \multirow[t]{2}{*}{ Sex } & Male & $70(53.8)$ & $28(21.5)$ & $>0.05$ \\
\hline & Female & $60(46.2)$ & $32(24.6)$ & \\
\hline \multirow[t]{2}{*}{ Preop hemoglobin } & $\leq 9 \mathrm{~g} / \mathrm{dL}$ & $18(13.8)$ & $14(10.8)$ & $<0.05$ \\
\hline & $>9 \mathrm{~g} / \mathrm{dL}$ & $112(86.2)$ & $46(35.4)$ & \\
\hline \multirow[t]{2}{*}{ Comorbidities } & Yes & $36(27.7)$ & 15 (11.5) & $>0.05$ \\
\hline & No & $94(72.3)$ & $45(34.6)$ & \\
\hline \multirow[t]{5}{*}{ Indication of surgery } & Degenerative & $61(46.9)$ & $14(10.8)$ & $<0.05$ \\
\hline & Trauma & $26(20)$ & $14(10.8)$ & \\
\hline & AIS & $20(15.4)$ & $14(10.8)$ & \\
\hline & Infection & $8(6.2)$ & $5(3.8)$ & \\
\hline & Others & $15(11.5)$ & $13(10)$ & \\
\hline \multirow[t]{4}{*}{ Surgical approach } & Posterior & $69(53.1)$ & $41(31.5)$ & $<0.05$ \\
\hline & Anterior & $42(32.3)$ & $6(4.6)$ & \\
\hline & Circumferential & $10(7.7)$ & $7(5.4)$ & \\
\hline & Lateral & $9(6.9)$ & $6(4.6)$ & \\
\hline \multirow[t]{5}{*}{ Region of spine } & Cervical & $43(33.1)$ & $5(3.8)$ & $<0.05$ \\
\hline & Lumbar & $42(32.3)$ & $25(19.2)$ & \\
\hline & Thoracolumbar & $30(23.1)$ & $21(16.2)$ & \\
\hline & Thoracic & $10(7.7)$ & $7(5.4)$ & \\
\hline & Cervicothoracic & $5(3.8)$ & $2(1.5)$ & \\
\hline
\end{tabular}

The $\mathrm{C} / \mathrm{T}$ ratio was derived by:

$\mathrm{C} / \mathrm{T}=$ No. of units of blood cross - matched /

No. of units of blood transfused $=510 / 112=4.5$

\section{Discussion}

Significant perioperative blood loss and major transfusion needs have traditionally been linked with spine surgeries. ${ }^{3-5}$ With a growing trend to reduce the requirement for allogenic blood transfusion, many blood-saving strategies have been used to decrease the criteria for transfusion in patients with spinal surgery. Preoperative allogeneic donating blood, proper patient placement, and sufficient muscle weakness have been used to reduce intra-abdominal stress, paravertebral tissues infiltration with epinephrine, intraoperative blood rescue, regulated hypotensive anesthesia, and antifibrinolytic agent usage. ${ }^{6-11}$ Current understanding of the risks associated with allogeneic blood transfusion has been increased, such as allergenic reactions, hemolytic reactions, increased rates of infection, and transmission of diseases especially human immunodeficiency viruses and hepatitis viruses. ${ }^{12-16}$ 
Table 4: Multivariate analysis of factors associated with a higher risk of transfusion in patients

\begin{tabular}{|c|c|c|c|}
\hline Parameters & & $\begin{array}{l}\text { Odd ratio ( } 95 \% \text { confidence } \\
\text { interval) }\end{array}$ & $p$ value \\
\hline \multirow[t]{2}{*}{ Age (in years) } & $\leq 40$ & 1 & - \\
\hline & $>40$ & $5.14(0.43-8.21)$ & 0.251 \\
\hline \multirow[t]{2}{*}{ Sex } & Male & 1 & - \\
\hline & Female & $2.59(1.52-578)$ & 0.483 \\
\hline \multirow[t]{2}{*}{ Preop hemoglobin } & $\leq 9 \mathrm{~g} / \mathrm{dL}$ & 1 & - \\
\hline & $>9 \mathrm{~g} / \mathrm{dL}$ & $3.48(0.63-6.36)$ & 0.372 \\
\hline \multirow[t]{3}{*}{ Comorbidities } & Hypertension & 1 & - \\
\hline & Diabetes mellitus & $1.96(0.16-3.23)$ & 0.614 \\
\hline & Ischemic heart disease & $1.28(0.84-2.78)$ & 0.728 \\
\hline \multirow[t]{5}{*}{ Indication of surgery } & Degenerative & 1 & - \\
\hline & Trauma & $1.12(1.01-1.25)$ & 0.014 \\
\hline & AIS & $1.61(1.43-1.83)$ & 0.017 \\
\hline & Infection & $1.70(1.15-2.50)$ & 0.001 \\
\hline & Others & $1.42(1.26-3.60)$ & 0.037 \\
\hline \multirow[t]{4}{*}{ Surgical approach } & Posterior & 1 & - \\
\hline & Anterior & $1.10(0.99-1.22)$ & 0.482 \\
\hline & Circumferential & $0.97(0.82-1.16)$ & 0.716 \\
\hline & Lateral & $1.39(0.85-2.31)$ & 0.862 \\
\hline \multirow[t]{5}{*}{ Region of spine } & Cervical & 1 & - \\
\hline & Lumbar & $0.75(0.54-1.03)$ & 0.091 \\
\hline & Thoracolumbar & $0.81(0.61-1.09)$ & 0.425 \\
\hline & Thoracic & $1.17(0.45-2.85)$ & 0.514 \\
\hline & Cervicothoracic & $1.23(1.00-1.51)$ & 0.613 \\
\hline
\end{tabular}

In the present study, most of the cases (53.84\%) did not required transfusions of blood and the quantity of blood crossmatched far surpassed the necessity. Out of 510 blood units cross-matched for our 130 cases, only 112 units were transfused to 60 cases, demonstrating that only $46.15 \%$ of cases require blood transfusions. For developing countries such as India, where health care is already restricted due to financial constraints, this was obviously an eye-opener; such a large waste of valuable resources, including time, money, equipment, workers, and storage space, was carried on for years on an unnoticed daily basis. This was especially important for surgeries carried out for routine degenerative spine pathologies such as lumbar microdiscectomy, laminectomy, cervical laminectomy, anterior cervical discectomy, etc. Interestingly, these are also the most common elective cases of the spine and do not involve perioperative transfusions in general.

A variety of variants were being suggested to be correlated with elevated transfusion demands in the literature, ${ }^{17-19}$ including low preoperative hemoglobin, history of pulmonary disease, tumor surgery, increased number of fused spinal levels, female gender, age $>60$ years, and a preoperative ASA score of 3 years. In the present study, variables related with a greater risk of blood transfusion were preoperative hemoglobin, indication of surgery, surgical approach, and region of spine $(p<0.05)$ by the Chi-square test. This is comparable with the study done by Alam et al. ${ }^{1}$ In contrast to the cervical spine, the lower regions of the spine (thoracic, thoracolumbar, and lumbar) were more likely to require transfusion, which is understandable considering the physical variations. This finding is correlated with the study done by Alam et al. ${ }^{1}$ and TorresClaramunt et al. ${ }^{19}$
The multivariate analysis revealed that the variables that were individually related with higher risk of blood transfusion was sign of surgery $(p<0.05)$, which is comparable with the study done by Alam et al. ${ }^{1}$ Taking degenerative spine surgery as the reference category in indication of surgery, the odds ratio of other indication of surgery requiring transfusion were calculated. It was found that as compared to degenerative spine surgery, trauma patients require 1.12 ( $p$ value 0.014 ), adult idiopathic scoliosis requires 1.61 ( $p$ value 0.017 ), infection patients require 1.70 ( $p$ value 0.001 ) blood transfusions, which were statistically significant.

The current study found the high $\mathrm{C} / \mathrm{T}$ ratio indicates that there was excess ordering of cross-matching than the number of units transfused. While TI was derived as 0.86 and the \%T was $46.2 \%$, which indicates effective blood utilization practices at our institution. Similarly, Alam et al. ${ }^{1}$ reported high $\mathrm{C} / \mathrm{T}$ ratios $(\mathrm{C} / \mathrm{T}$ ratio $=4.4: 1)$ and those undertaking arthrodesis for progressive disease (6.9:1) or cervical spine arthrodesis (23:1) had the maximum C/T ratios representing an important defect in their blood collection practice. Arinze et al. ${ }^{2}$ found $\% \mathrm{~T}$ of the spinal surgeries $45.8 \%$, TI derived was 0.7 , and $\mathrm{C} / \mathrm{T}$ ratio was 3.4 ; these findings are similar to the present study.

An innovative approach is needed to minimize the allogeneic transfusion demands of spinal surgical patients and to improve perioperative patient care, as blood management is definitely a complex problem. The present retrospective observational study among 130 patients in a tertiary hospital was conducted to audit the blood transfusion practice during intraoperative period for adult spine surgery to evaluate the blood transfusion practice; however we did not aim to develop any institutional guideline. 


\section{Limitation of Study}

- In our research, even days after the procedure, certain blood units that were very likely to be transfused postoperatively in the wards were not calculated on the basis of transfusion rate and blood utilizations indices.

- The present study is limited as retrospective design and representing only our institutional practices. Therefore, these results cannot be generalized.

\section{ConcLusion}

After evaluation of audit of blood transfusion practices in adult spine surgeries, we observed that factors associated with blood transfusion were preoperative hemoglobin, indication of surgery, surgical approach, and region of spine by Chi-square. The multivariate analysis showed that the independent factor associated with more number of blood transfusions was indication of surgery.

Transfusion probability and TI in the present study are indicative of optimal utilization of blood. However, the high C/T ratio suggests the over cross-matching, which should be minimized in future.

\section{References}

1. Alam MM, Sobani ZA, Shamim MS, et al. Primary elective spine arthrodesis: audit of institutional cross matched to transfused (C/T) ratio to develop blood product ordering guidelines. Surg Neurol Int 2013;4(5):S368-S372. DOI: 10.4103/2152-7806.120778. https://www. ncbi.nlm.nih.gov/pubmed/24340234.

2. Arinze DGN, Ugochukwu NE, Ikechukwu CO, et al. Audit of blood transfusion practice during anaesthesia for spine surgeries in a regional trauma centre in Nigeria. Orient J of Medicine 2015;27(34):65-70. https://www.ajol.info/index.php/ojm/article/view/131352.

3. Johnson RG, Murphy M, Miller M. Fusions and transfusions. An analysis of blood loss and autologous replacement during lumbar fusions. Spine 1989;14(4):358-362. DOI: 10.1097/00007632-198904000-00002. https://europepmc.org/abstract/med/2718036.

4. Bess RS, Lenke LG. Blood loss minimalisation and blood salvage techniques. Neurosurg Clin N Am 2006;17(3):227-234. DOI: 10.1016/j.nec.2006.04.009. https://www.ncbi.nlm.nih.gov/pubmed/ 16876024.

5. Wass CT, Long TR, Faust RJ, et al. Changes in red blood cell transfusion practice during the past two decades. Transfusion 2007;47(6):10221027. DOI: 10.1111/j.1537-2995.2007.01231.x. https://www.ncbi.nlm. nih.gov/pubmed/17524092.

6. Zheng F, Cammisa Jr FP, Sandhu HS, et al. Factors predicting hospital stay, operative time, blood loss, and transfusion in patients undergoing revision posterior lumbar spine decompression, fusion and segmental instrumentation. Spine (Phila Pa 1976) 2002;27(8):818824. DOI: 10.1097/00007632-200204150-00008. https://www.ncbi. nlm.nih.gov/pubmed/11935103.
7. Cha CW, Deible C, Muzzonigro T, et al. Allogenic transfusion requirements after autologous donations in posterior lumbar surgeries. Spine (Phila Pa 1976) 2002;27(1):99-104. DOI: 10.1097/00007632-200201010-00023. https://www.ncbi.nlm.nih. gov/pubmed/11805645.

8. Elwatidy S, Jamjoom Z, Elgamal E, et al. Efficacy and safety of prophylactic large dose of tranexamic acid in spine surgery: a prospective, randomized, double-blind, placebocontrolled study. Spine (Phila Pa 1976) 2008;33(24):2577-2580. DOI: 10.1097/BRS.0b013e318188b9c5. https://www.ncbi.nIm.nih.gov/ pubmed/19011538.

9. Goodnough LT, Shander A, Brecher ME. Transfusion medicine: looking to the future. Lancet 2003;361(9352):161-169. DOI: 10.1016/S01406736(03)12195-2. https://www.ncbi.nlm.nih.gov/pubmed/12531595.

10. Lawson JH, Murphy MP. Challenges for providing effective hemostasis in surgery and trauma. Semin Hematol 2004;41(1 Suppl):55-64. DOI: 10.1053/j.seminhematol.2003.11.012. https://www.ncbi.nlm.nih.gov/ pubmed/14872423.

11. Porte RJ, Leebeek FW. Pharmacological strategies to decrease transfusion requirements in patients undergoing surgery. Drugs 2002;62(15):2193-2211. DOI: 10.2165/00003495-200262150-00003. https://www.ncbi.nlm.nih.gov/pubmed/12381219.

12. Eckardt JJ, Gossett TC, Amstutz HC. Autologous transfusion and total hip arthroplasty. Clin Orthop Relat Res 1978(132):39-45. DOI: 10.1097/00003086-197805000-00009. https://www.ncbi.nlm.nih. gov/pubmed/679550.

13. Gilbett ER. Blood group alloantibodies: an assessment of some laboratory practices. Transfusion 1977;17(4):299-308. DOI: 10.1046/j.1537-2995.1977.17477216857.x. https://www.ncbi.nlm.nih. gov/pubmed/406699.

14. Goodnough LT, Marcus RE. Effect of autologous blood donation in patients undergoing elective spine surgery. Spine (Phila Pa 1976) 1992;17(2):172-175.DOI: 10.1097/00007632-199202000-00009. https:// www.ncbi.nlm.nih.gov/pubmed/1553588.

15. Kruger LM, Colbert JM. Intraoperative autologous transfusion in children undergoing spinal surgery. J Pediatr Orthop 1985;5(3):330332. DOI: 10.1097/01241398-198505000-00014. https://www.ncbi.nlm. nih.gov/pubmed/3923036.

16. Lisander B, Jonsson R, Nordwall A. Combination of bloodsaving methods decreases homologous blood requirements in scoliosis surgery. Anesth Intensive Care 1996;24(5):555-558. DOI: 10.1177/0310057X9602400508. https://www.ncbi.nlm.nih.gov/ pubmed/8909665.

17. Guay J, Haig M, Lortie $L$, et al. Predicting blood loss in surgery for idiopathic scoliosis. Can J Anaesth 1994;41(9):775-781. DOI: 10.1007/ BF03011583. https://www.ncbi.nlm.nih.gov/pubmed/7954993.

18. Nuttall GA, Horlocker TT, Santrach PJ, et al. Predictors of blood transfusions in spinal instrumentation and fusion surgery. Spine (Phila Pa 1976) 2000;25(5):596-601. DOI: 10.1097/00007632-20000301000010. https://www.ncbi.nlm.nih.gov/pubmed/10749636.

19. Torres-Claramunt R, Ramírez M, López-Soques M, et al. Predictors of blood transfusion in patients undergoing elective surgery for degenerative conditions of the spine. Arch Orthop Trauma Surg 2012;132(10):1393-1398. DOI: 10.1007/s00402-012-1563-y. https:// www.ncbi.nlm.nih.gov/pubmed/22707213. 